\title{
The Relative Age of Endemic Species and other Controversial Points.
}

\author{
BY
}

\section{J. C. WILLIS, M.A., Sc.D.}

$\Upsilon \mathrm{N}$

$\mathrm{N}$ a recent number of this journal there is a paper by $\mathrm{Mr}$. H. N. Ridley

(1) in which he expresses great dissatisfaction with the hypothesis of 'age and area' which I have elsewhere $(5,6,7)$ brought forward as being, in my opinion, a general rule which has governed the distribution of the Angiosperms (and some animals at any rate) about the globe. Mr. Ridley also sets forth the case from the Natural Selection point of view ; for there is no doubt that the adoption of my hypothesis involves a final abandonment of Natural Selection as seriously operative in this direction. Whatever it may, and doubtless does, effect in individual cases, its results are not sufficiently marked to show themselves in my figures, which deal with large numbers and the long run, and are similar to one another for all groups of plants. Mr. Ridley's paper was evidently written before seeing my subsequent paper on the flora of New Zealand (7), or much that it contains might have been omitted, or left for further consideration.

I shall take Mr. Ridley's points, as given in his summary, in order, paying special attention to the supposition often brought forward, that endemics are chiefly the relics of an old flora; and shall also give further evidence for my hypothesis, which if once fully accepted, will make a great difference in the handling of questions of geographical distribution and evolution at least, if not in other lines of work.

In the earlier portion of his paper Mr. Ridley seems to me to imply that my numerical results are accidental. But, as I have already pointed out, the probabilities against such a thing are inconceivably great. In the first place we have to note the very remarkable fact that the same accident would appear to have happened to all, and we have now the further case of New Zealand, where instead of the estimates of the Ceylon flora I have used actual longitudinal range in the islands, and where every family and genus (for even the genera with one or two species follow the grouping as accurately as those with more, which are quoted in the tables) behaves in the same way. Ceylon is quite put into the shade by the way in which the flora of New Zealand follows my hypothesis. 
Mr. Ridley then goes on to suggest that the figures depend upon the number of specimens in the herbarium, which, if it were literally true in detail, and my Ceylon work were not supported by that upon New Zealand, would be a very damaging criticism. I was careful before publishing, however, to verify that Trimen's figures (4) did, as a matter of fact, in most cases, indicate roughly the area occupied. He does not count duplicates from the same place, and goes, to the extent of perhaps 80 per cent., upon the results already obtained by Thwaites (3), who did the lion's share of the investigation of the Ceylon flora, and that chiefly in the days before there was such extensive clearance for planting. Mr. Ridley complains that investigation stopped with Trimen, but if he will refer to my annual report for 1910 he will find an enumeration of the herbarium, showing that while Thwaites added 6,492 sheets, Trimen added 2,890, and I myself 1,603 . But with all the additions since Thwaites's time, the range in Ceylon of the various species has been comparatively little extended. The serious additions to localities made in my time are summed up in a paper by Mr. A. M. Smith and myself (19), but these were completely ignored in my papers under discussion, which are based solely on Trimen's flora. Taking $3^{6}$ consecutive species at random from Thwaites, and giving them marks according to area as in Trimen, I found that they received I I 5 marks in the former, 100 in the latter case, and this I think fairly enough represents the general difference that Trimen's work made in regard to the geographical distribution of the species of Ceylon; 13 of the 36 are moved one place up by Trimen, and 12 remain the same ; 6 go down a place, and the remaining 5 make larger moves.

That Trimen's figures do as a matter of fact very fairly indicate area is shown by the maps given on p. $12(6)$; about 10-I 5 per cent. of the VR, 5-IO of the $R$, and smaller proportions of the higher classes are in my opinion wrongly placed, and should be moved up, usually one class. But this movement would make no difference in the figures, as may be easily shown. Let us move up I 5 per cent. of the VR species, then Io per cent. of the increased R's (to allow for the few VR's that should go more than a class upwards), then 5 per cent. of the RR's, and 2 per cent. of the RC's. The result is to replace the table on p. $3(6)$ by the following:

TABLE I.

$\begin{array}{rccc} & \text { Endemic. } & \text { Ceylon-Penins. India. } & \text { Wide. } \\ \text { VC. } & 19 & 45 & 221 \\ \text { C. } & 93 & 120 & 468 \\ \text { RC. } & 144 & 105 & 318 \\ \text { RR. } & 162 & 86 & 216 \\ \text { R. } & 191 & 68 & 163 \\ \text { VR. } & 198 & 68 & 122 \\ \text { Rarity } & 4^{\circ 2} & 3.4 & 3.0\end{array}$


a change of 0.1 in the rarity of the endemics and the Ceylon-Indians, which makes no difference to their validity for my argument.

Mr. Ridley further goes on to state that future work on the Ceylon flora will so modify the results obtained from Trimen that any deductions based upon the latter will be valueless. I have already shown how little difference Trimen's work made in Thwaites's results. My own made still less in Trimen's, and the differences will decrease as time goes on. As I have already stated, the effect of the completion work, when once a flora, like that of Ceylon or New Zealand, is reasonably well worked out, is to add new species to the class VR, to move a few VR into $R$, rather fewer $R$ into $\mathrm{RR}$, and so on in decreasing proportions up the scale. But this leaves the ultimate result the same as before.

In any case the Ceylon figures, estimates though they be, are shown to be fairly accurate and reliable by the fact that they come out with such arithmetically regular gradations along the scale in opposite directions for endemics and wides; and this is amply confirmed by the fact that the New Zealand figures, which give actual measurements, agree with them.

I much regret that in my Ceylon papers I did not make sufficiently clear the various conditions that might modify the action of my age and area rule. Partly this was because I thought that many were obvious, and partly because I was thinking more of making the law itself clear. In later papers I have instanced various such conditions, and Mr. Ridley's paper is also of great service in this respect. In the New Zealand paper (7), p. 449, I have said that 'the vast flora of introduced weeds may be left out of account, for there is not the least evidence to show that they would have spread had not foreign conditions, or disturbance of the native conditions, been also introduced', whilst in a paper which I read to the Linnean Society last year I went into this question in detail, analysing the flora of introductions into Ceylon which I have elsewhere published (8). This list contains $3^{87}$ plants, and I showed that there was no evidence of spread without alteration of conditions except in four cases. Here the spread is but small, and in at least two has been indirectly assisted by man.

It is evident that if man arrive in a country and make extensive clearances, allowing the spread of introduced weeds like the lalang (cf. I, p. 572), the operation of my law of age and area must be interfered with. For this reason, remembering how much of 'dry' northern and eastern Ceylon was once occupied by agriculture, I do not think that the detailed list of its flora as now made up is very complete, though, owing to the configuration of the island, and the direction of the monsoons, I cannot for one moment admit that this country was ever covered with 'wet-zone' forest. Even there, however, there was a good deal of forest left, while the bulk of the Ceylon flora, whether 'wide' or endemic, lies in the south-west, which at the time of Thwaites was comparatively little encroached upon. 
Mr. Ridley does not fully realize that my figures, though it is definitely so stated in several places, refer to area occupied, not to commonness on the ground. On p. $55^{2}$ he quotes the two Hedychiums as instances of VC species which have now died out at Peradeniya, showing a lack of apprehension of the real drift of my argument. To begin with, he quotes them both as VC, but if he will take the trouble to look again at Trimen's Flora, he will see that this is not quite correct. In the second place, it is not difficult to find them near Peradeniya, though not perhaps on the Kandy road, which is now practically a suburban street. The area occupied by these species remains as before, though evidently the operations of man have reduced their commonness within that area. But even if they were nonexistent now in the places where man has introduced a change of conditions, that would not in any way affect my argument, which refers to action under constant conditions. The incoming of man may easily produce as great changes as a change of climate or other geological change, and I much regret that in my earlier statements of the law I did not lay more stress upon the many conditions that may modify its action, as for example by the use of such a covering phrase as 'so long as conditions remain unaltered', but somehow this seemed to me so obvious that it was unnecessary. If a powerful magnet be placed near to the line of fall, it is obvious that an iron ball will not fall in exact accord with the law of gravity, but that fact does not alter the validity of the law.

We may therefore dismiss from further consideration here all such cases as are brought up by Mr. Ridley showing the effects of man's action in the spread of species, or in their destruction, and go on to a further objection raised against the species which Trimen labels VC. Mr. Ridley would apparently regard most of these as also introduced by man. This is, I think, somewhat sweeping. In my Catalogue I have marked by an asterisk those which Trimen or I think to have been possibly or probably so introduced, and they number $5^{2}$ out of 285 , showing rarities VC $12, \mathrm{C} 25$, $\mathrm{RC}_{5}, \mathrm{RR} 2, \mathrm{R}_{4}, \mathrm{VR} 4$, giving a mean rarity of $2 \cdot 4$. Subtraction of all of them makes no difference at all in my figures. But in order to satisfy Mr. Ridley, let us omit all the $285 \mathrm{VC}$ 's, thus reducing the flora to five classes. Instead of 809 endemics with $3,5^{1} 8$ marks, we get 790 with 2,709 ; instead of 492 Ceylon-Indians with I,7 I4 marks, we get 447 with I,222, and instead of $I, 508$ wides with 4,579 marks, we get $I, 287$ with $3,07 \mathrm{I}$. These, calculated out, give rarities of $3 \cdot 4,2 \cdot 7$, and $2 \cdot 3$, in figures running from I to 5 only. These are just as useful for my deductions as those actually employed, and the omission of the whole $285 \mathrm{VC}$ species makes no important difference.

The same remarks as have been made upon the effects of the action of man apply to the effects of a change of climate, which in my New Zealand paper, p. 456 , I mentioned as one of the factors causing modification. It is obvious that if a serious change of climate occurs-usually in consequence 
of some geological change-it will make a difference in the spread of a given set of species about a given area. Mr. Ridley demands geological catastrophes, but apparently (p. 557) even the glacial period is not sufficient.

No one who is unaccustomed to the handling of statistics of large numbers can perhaps easily realize how unassailable my figures actually are. If we move up one half of every class, we still get rarity figures of $3 \cdot 8,3 \cdot 0$, and $2 \cdot 6$. One must not arbitrarily move up endemics without moving up wides, and the figures cannot be equalized unless all are placed in the VC class, which is an obvious impossibility under Natural Selection, and on my hypothesis could not in any case occur unless the appearance of new species (wide or endemic) were stopped, and perhaps 60,000 further years allowed, as indicated in a valuable paper by Mr. Ridley (2).

The figures given will suffice to show the weakness of Mr. Ridley's attack upon my position. To quote exceptions, as he does, makes no difference. He need not have searched the world for them, but might have found them by the dozen in Trimen's Flora. Probably in about a third of. the cases the actual figure there given does not represent the real truth, but that does not invalidate the argument, which simply goes to show that the overwhelming factor in distribution is age, though many other factors are continually at work. Pulling this way and that, however, and not acting upon whole groups of allied forms in the same way, their effects do not show in the figures.

Mr. Ridley quotes about seventy cases in various connexions. Many of these, e.g. those on p. 555, are excellent illustrations of what I have said (6) on p. 22, that a very small accident may kill out a species in the class VR. In others he sets out to show that VC species may easily disappear, but only shows that they have disappeared in particular localities. But for the sake of argument let us accept all these cases as showing each that one of my wides is five classes too high. Then instead of 4,579 marks for the I,508, we get 4,929 (i. e. by adding $35^{\circ}$ ), and a rarity of 3.2 instead of $3 \cdot \circ$. Or, to make the case as strong as possible, let us omit all the VC species, which Mr. Ridley thinks are introduced, and divide the seventy into two, one half moving the wides down as much as possible, the other the endemics up. Even then, a little calculation will show that the rarities come out (in figures I to 5) $3 \cdot 2,2.7$, and 2.4. My arguments could be carried on from these figures just as effectively as from those that were actually used.

Unless Mr. Ridley can produce large numbers of cases which all move the wides down and the endemics up, it is idle waste of time to bring up exceptions. But the case no longer rests upon estimates; these have been replaced by actual measurements in the case of New Zealand, and Mr. Ridley would have to show that 902 endemics, but no wides, were each under- 
estimated in range by 360 miles. $^{1}$ Even for Ceylon, to equalize the figures $(6$, p. 4) 687 endemics must go up a class, which means discovery in new localities, and 699 wides must go down a class, which means proof of wrong identification for localities already recorded.

The New Zealand figures confirm those of Ceylon to the necessary degree of safety. The Ceylon figures served their purpose in drawing my attention to the law of age and area which I based upon them. Had it not been that the species were thus conveniently classified into groups, I doubt if I should have thought it worth while to undertake the enormous labour of determining the area occupied by each, though I was determined to find out all that could be found out about the endemics.

To apply my law to individual cases is to invite mistake, but no amount of evidence of individual exceptions will shake it. Exceptions must be brought up in groups of twenty allied species, behaving alike. Assuming that lalang were native (see 1, p. 572) and spread without alteration of the previous conditions, no argument can be based upon it unless it were accompanied by nineteen other exceptional Gramineae. Even the other species of Imperata is VR, which at once halves the commonness of the lalang.

Exceptions occur by the dozen, but there is no evidence in the figures to show that similar exceptions form any large percentage. Probably there are a fair number of relic endemics, of cases where adaptation really occurs, of cases where Natural Selection has been beneficially in operation, and the like, but they do not show in the figures, which simply go to show the overwhelming effect of mere age.

\section{Relative Age of Endemics and Wides.}

$\mathrm{Mr}$. Ridley further states that the endemics are nearly all the relics of an old flora rapidly disappearing, and thus brings up the line of opposition which so far I have most frequently encountered. With the view of replying to it in advance, I read at the Newcastle meeting of the British Association a paper with the title 'Are endemics the oldest or the youngest species in a country?' and I shall now proceed to quote a considerable portion of this paper, as Mr. Ridley's objection would obviously make them out to be the older species.

'In several papers recently published, I have brought forward a law which I propose, indicating that the geographical distribution of species (taken in groups of twenty or so allied forms) depends chiefly upon their age within the country, Natural Selection, whatever results it may produce in 120 miles,

1 Rarity of wides 3.5 , of endemics 6.5 , in figures from I to 10 . Each unit represents 
individual cases, being apparently of no effect when dealing with many allied species. This law, once stated, has evidently to be hedged round with various provisos, indicating the various causes which may modify its action. One, for example, which seemed to me so obvious that I did not mention it specifically, was that the law would only be strictly operative so long as the conditions remained constant-a change of climate or submergence of part of the country would clearly modify its operation.

'So long as the law was only based upon the estimates given for distribution in Ceylon, so long was its foundation somewhat precarious, and as soon as possible I worked out another flora, that of New Zealand, but with actual distances of spread instead of estimates. This gave confirmatory evidence of the most satisfactory kind, the graduation of the endemic species from few of large spread down to many of small, and of the wides in the opposite direction, being very clearly shown, while at the same time the prediction which I made, that if New Zealand were divided into equal zones the endemic species would appear in them in numbers graduated up to a maximum (or sometimes two), was borne out by the facts in the most convincing manner, leaving no room for doubt that Natural Selection could not be the operative factor in causing their distribution.

'That the longer a species has been in a country, the more area it should occupy, does not seem to be an unreasonable nor far-fetched explanation, but it leaves out of account the structural differences between species, and ignores Natural Selection, and thus runs much against the grain to many botanists, who still base their arguments (though often more or less unconsciously) upon it. In particular they have long been accustomed to look upon the endemic species of small areas as being the oldest in a country, instead of the youngest, and as being in some way expressly suited to the local conditions, though when pressed they are not able to suggest any very clear reason for their belief. There is nothing in the structure of most endemic plants to show that they are in any way adapted to local conditions, nor that they are any older than the species of wider distribution that accompany them, though not seldom something to show the contrary.

'The essential facts which have to be explained in the floras of Ceylon and New Zealand (and observation on other floras shows that they are very general ${ }^{1}$ ) are that the endemic and the widely distributed species in a given country are arranged in graduated series, showing an increase in number in opposite directions, the endemics increasing from those of wide to those of narrow distribution, the wides in the other direction. I have already shown that Natural Selection cannot account for such regular arrangement of distribution, which shows not only on the total, but also family by family.

1 The case of England, or of other countries which have been completely altered by man, must be dealt with separately. The advent of man may soon become as important as a geological catastrophe or a serious change of climate. 
Some mechanical cause must be responsible, and for that cause I have suggested age.

'Several botanists, while admitting that my figures are not to be gainsaid, are of opinion that my results can be equally well explained by reversing my hypothesis, and considering that youth, rather than age, is responsible for the occupation of large area. I shall try to show that this conception leads logically to an untenable position, and shall also give some crucial test cases, which speak in favour of age.

'Age is an obvious reason for occupying a large area, but youth is not, and we shall require stronger evidence to prove the latter. Obviously it must not be pushed to extremes, and a supplementary hypothesis will be needed to account for the fact that the very latest arrivals are not the commonest species.

'My hypothesis is based upon age within the country. What the species may have done in the way of spreading in other countries, or where it was evolved, and when, is immaterial ; when it arrives in the country with which we are dealing, it commences to spread, if suitable to the climate and soil, and spreads over an area determined, so long as conditions remain constant, and except in so far as barriers of mountains, broad rivers, sudden changes of climate from one region to another close by, and the like, interfere, by the length of time during which it has been in the country. ${ }^{1}$

'If, however, one try to reverse the hypothesis, one has at once to make choice of two cases. Either the supposition must be that area occupied depends upon youth within the country, or upon absolute youth. The exact reversal of my hypothesis of course gives the first case.

' On either view a great difficulty arises from the fact that the wides and endemics both show a graduated order of rarity, the former from many of large area to few of small, and the latter in the reverse direction. This fact, which in the Ceylon flora depended upon estimates, shows with actual measurements for New Zealand. There is thus nothing for it but to admit that my hypothesis must be reversed in detail, and that the younger a species is, whether absolutely or within the country, the greater area will it occupy. The same thing follows necessarily from the fact that in Ceylon the species common also to Peninsular India are intermediate in rarity between the endemics and the wides. Whatever hypothesis be adopted, one must admit that these species are intermediate in youth as in rarity.

- A great difficulty for the hypothesis of absolute youth is the fact that the range in Ceylon in no way corresponds with the range outside of it, as one might expect upon this supposition. Sanicula europea, for example, and many other species have a vast range outside of Ceylon, and on this hypothesis are therefore presumably very young, yet within Ceylon only

1 It being of course understood that the law does not necessarily apply to individual cases, any more than Mendel's Law, but to groups of allied forms. 
occupy each one restricted locality. Polyalthia Korinti, Garcinia spicata, Impatiens oppositifolia, and forty other species common only to Ceylon and Peninsular India (often only a small southern part of it), and whose absolute range is thus small, presumably indicating age, are yet very common (and therefore presumably very young?) in Ceylon. Eugenia rotundifolia (endemic) is very common in Ceylon, and thirteen other endemic Eugenias are very rare. Are the latter very old, the former very young ?'

'The hypothesis of youth and area, when the youth is to be absolute youth, cannot be established without calling in Natural Selection of a somewhat remarkable kind. But as I have already pointed out $(6, \mathrm{pp} .6-\mathrm{r} 6)$, Natural Selection must explain the very difficult problem, why every family and genus, in New Zealand as well as Ceylon, shows similar arithmetical arrangement of its species according to the area they occupy.

'We are thus driven to accept the youth hypothesis in the form that it is youth within the country, or exactly to reverse my hypothesis of age and area. But if we do so accept it, we are at once brought up short by the question why? What conceivable reason can be given to explain why the two things should be connected? The case of the rapid spread of introduced weeds in islands like Ceylon or New Zealand is often quoted as evidence that foreign species recently introduced spread more rapidly than the local, but ignores three important facts at least: (I) that foreign conditions have also been introduced, e. g. by cutting down of forest, or in other ways ; (2) that such weeds are also common in continental areas, as for example at Rio de Janeiro, where the local flora of $7,000-8,000$ species is one of the very richest in the whole world, and includes a vast number of species covering enormous areas of distribution, so that its members should be well able to hold their own, and (3) that where they have spread, it has been just as much at the expense of the wides already in the country as of the endemics.

' To return to the main argument, why should a species which is very old (and therefore on this hypothesis very rare) in, let us say, South India, at once spread over a large area if it arrive in Ceylon? Or, to take a concrete case, suppose that Coleus elongatus, which at present is confined to the summit of Ritigala (9) in Ceylon, and shows no signs of spreading thence, occurred not on Ritigala, but on one of the hills of South India. Would it at once spread if brought into Ceylon, and if not, why not? Has it at one time existed all over Ceylon, and is the soil of that country now permanently Coleus elongatus-sick? Or take it the other way: if carried from Ceylon to South India, would it at once spread? If not, why not?'

Mr. Ridley prefers to consider the endemics as the oldest species in a country. But he must in any case admit that the species confined to Ceylon and Peninsular India, which are intermediate, in area occupied, between the endemics and the wides, are intermediate also in age. We are 
thus confronted with a very remarkable case when we deal with such a gigantic and universal genus as Senecio, which has hundreds of endemic species in all corners of the earth-Ceylon, New Zealand, Peru, Europe, North America, \&c., \&c., as well as hundreds of species occupying intermediate areas, and a few occupying large ones. Where did the last-named come from, and at what particular size does a species cease to be one of the doomed, and become an extending and conquering species? Take the case of Cordia in Ceylon. C. Myxa, which occurs all over the eastern tropics, is $\mathrm{C}$ (common), but $C$. monoica, which only occurs in Peninsular India, is also $\mathrm{C}$, while $C$. Rothii, which occurs in Peninsular India, Arabia, and Abyssinia, is only $\mathrm{R}$, and $C$. subcordata, found on most eastern tropical coasts, is VR. C. monoica is only endemic to a small area and ought to be one of the doomed; why is it common? What, on Mr. Ridley's views, settles the fate of a species in a country?

The hypothesis of youth (within the country) and area can only be accepted if one be prepared to accept with it the numerous absurdities to which it leads. It is very far-fetched, with no facts to rest upon, and involves a most remarkable amount of rising and falling in the scale of commonness (area of distribution) for which we have no warrant. In fact, it seems to me to require direction of evolution from outside, and in a very remarkable manner. A forthcoming paper, dealing with the distribution of the plants of the outlying islands of New Zealand, seems to me to finally decide the question against it.

Mr. Ridley goes on to state that the endemics must be old, because there is nothing in the land from which they could have been evolved. This is a most remarkable statement, when one remembers that most of them have 'wides' in the same genus. He accuses me of omitting from a list of genera, definitely described as? containing five or more endemic species, the monotypic endemic genera, which he will find given in detail in Table XVII of my earlier paper (5). He states that most of these are rare, but if he will look at the figures he will find that they are RR, $\mathrm{RC}, \mathrm{C}, \mathrm{RR}, \mathrm{C}, \mathrm{C}, \mathrm{R}, \mathrm{RC}, \mathrm{VR}, \mathrm{R}, \mathrm{R}, \mathrm{VR}, \mathrm{RC}, \mathrm{RR}, \mathrm{RC}, \mathrm{RC}, \mathrm{RC}$, giving a rarity of 3.7 , or considerably less than the endemics as a whole, and much below the rarity of the endemic genera with more than one species, which is 4.2 for those with two or three, 4.6 for Doona with eleven, and 5.4 for Stemonoporus with fifteen. The rarity of the endemic genera goes in the opposite direction to that which one would expect were they being killed out. Why should genera with many species be nearer extinction than those with one, and the nearer the more species they have?

Mr. Ridley also states that I do not mention the fact that there are many genera which contain only endemic species. These he will find given in detail in Table XXV of the same paper (5). Adding these up, he will find that they only total I69, out of the 809 Ceylon 
endemics. And they behave in exactly the same way as do the endemics in those genera which contain wides. Very many of them are as a matter of fact included in the tables on p. 8 (6) to which Mr. Ridley objects. Doona, Stemonoporus, Semecarpus, Acrotrema, Dipterocarpus, Shorea, Lasianthus, Palaquium, Gymnostachyum, Actinodaphne, Bulbophyllum, and Cirrhopetalum in these tables are all genera which contain no wides, but there is nothing in the figures to differentiate them from those which do.

With regard to these endemic species in genera that contain no wides, there are several very remarkable facts which place great diffculties in the path of Mr. Ridley. To begin with, their rarity is $4 \cdot 2$, or almost exactly the same as that of the endemic species in genera that contain wides, or, in other words, they are dying out at much the same rate as the latter. But if so, where does the Natural Selection theory, which implies that the competition will be more severe between species of the same genus, come in? And why are the species of endemic genera rarer than they, and that the more the more numerous they are in the genus? And in these endemics of genera with no wides, why $\left(5, \mathrm{p} .33^{\mathrm{I}}\right)$ is the rarity greater if the genus contains many species than if it contains few, exactly as is the case with the actual endemic genera?

The fact that genera occur with endemics and no wides is no doubt a difficult point to explain, but, as I have just shown, Natural Selection will not explain it. Probably the first arrivals from abroad mutated on arrival, finding themselves in somewhat different conditions, but what is now really wanted is a detailed examination of thousands of genera, to determine if possible the general principles on which specific differentiation occurs. I have made a commencement of this with the Ceylon genera, for example, and find that the endemics separate into three chief classes. The commonest may be roughly represented by a small circle within a larger, and goes on till one gets such a diagram as that of Doona (6, p. I4). The next is a small circle touching the large, but outside of it, and there are no materials in Ceylon to follow it farther. The third and last is a small circle at a small distance from the large, and this also cannot be followed any farther in Ceylon. As yet I have not had time to follow out these researches any farther, but I can see in them the possibility of obtaining a good deal of information of great value in the study of geographical distribution.

Why, if Natural Selection is of any avail, do the II 2 genera which have no competition with any other more widely distributed species nearly related to them, only contain 221 species, or less than 2 species per genus, while Ceylon as a whole has 2,809 species in 1,027 genera (average $2 \cdot 7$ ), and the remaining endemics, which have to compete with wides in their own genera, show 588 endemic species in 212 genera (average 2.7 also)?

The next question we have to consider is whether the endemics did 
or did not once occupy a greater area. The view adopted by Mr. Ridley apparently is that they are the relics of a once extensive flora which is being driven in.

But if 233 of the Ceylon endemics are VR relics of this flora, why are 222 wides also VR? Are they also relics? And why has Ceylon 222 such relics, while New Zealand has only 2I (with one-fifth the flora of wides), of which at least half have no right to be included in the list $(7$, p. 452) ? Why do the endemics choose mountain-tops to such an extent? Ceylon has I08 of them confined to summits or to small areas in the high mountains (12). Why has New Zealand proportionately fewer, and why in New Zealand do they comparatively rarely occupy one summit only, but more often a small range?

The usual theory of the supporters of Natural Selection is that they have gone up the mountains as the last refuges from the invading flora of the low country. But in such small and uniform countries as South-western Ceylon and New Zealand it is hardly possible to suppose that there was a separate Eugenia or Celmisia at every few miles. And why did they climb right to the summit? It suggests an unnecessary degree of alarm about the coming competition. Further, it would suggest that endemics are not so incapable of adaptation to new conditions that they need fear the competition at all. If they can undergo the great adaptive changes necessary to reach a summit of 3,000 to 10,000 feet, they must have a very fair capacity for modification, and should be able to hold their own.

Why are the wides which are VR in Ceylon, 222 in number, not found confined to mountain-tops? Are they not dying out, and, if not, why not, when they are as rare as the endemics which are supposed to be doing so? It suggests that they did not care to waste time in modification to suit high altitudes, when they were to be killed out in any case.

But the great difficulty of all, perhaps, for the supporter of Natural Selection is to explain why the dying out of the endemics (assuming that they are doing so) is purely mechanical. Why does every family and genus behave in the same way, whether it does or does not contain wides, and whether it be species in an endemic or in a widely distributed genus? Natural Selection could not cause a mechanical dying out unless it meant that the arrival of the first few widely distributed species (i. e. assuming that they are the younger and arrived later) was the signal for the dying out of the whole of the old flora. Why should a genus, as we have just seen, die out sooner than a species? Why should a genus die out in the regularly graduated way shown in the map of Doona $(6, \mathrm{p} .14)$, or in the Tables IV, $\mathrm{V}$, and VI of my last paper (7)? Why should the endemics be most numerous where there are most wides (see below, crucial case No. I)?

We shall now give two crucial cases (already given at Newcastle), which speak strongly for age against youth, and a third, still more con- 
clusive, is given in a forthcoming paper on the islands surrounding New Zealand.

I. Dispersal of Plants in Nerw Zealand. All the evidence goes to show that at one time the islands of New Zealand were continuous, but that at some time-whether before or after the separation from Australia is immaterial-they became separated by the formation in the centre of what is now termed Cook's Strait. If the endemics be the older, therefore, it necessarily follows that Cook's Strait would less often interfere with their dispersal through New Zealand than with the dispersal of the (younger) widely distributed species. Taking the distribution of the wides and endemics of New Zealand, zone by zone, in the same way as was done in my New Zealand paper (7), we find

$\begin{array}{clllllllllll}\text { Wides } & 209 & 210 & 237 & 237 & 235 & 242 & 236 & 227 & 215 & 204 & \text { II } 2 \\ \text { Endem. } & 234 & 280 & 330 & 368 & 386 & 537 & 532 & 527 & 516 & 414 & \text { I30 }\end{array}$

From the first line it is impossible to tell where Cook's Strait lies, whether after the 5 th, 6 th, or 7 th number, but a glance at the second line shows a great change after the 5 th, and this is in actual fact the position of Cook's Strait. Many endemics come up from the south and stick at the strait.

Similarly at Foveaux Strait, which comes between the last two figures, more than half the wides get across, and a much smaller proportion of the endemics. It is difficult to resist the conclusion that the wides, not the endemics, are the older.

Another very difficult problem for the supporter of Natural Selection is to explain why in this table the maximum of the wides coincides in position with that of the endemics. One would not expect to find this, if the former are driving in the latter. The same is the case in Ceylon; for more endemics occur in the wet zone, which also has by far the most wides. Even within the wet zone, the maximum number of both endemics and wides occurs in the same region.

Why, again, do both wides and endemics taper off with very fair regularity towards the ends of New Zealand, and why do the numbers taper down much more rapidly in the case of the endemics? While the wides sink from 235 to 209, the endemics sink from 386 to 234. Age and area will explain all this quite simply, but neither youth and area nor Natural Selection will do so.

2. Distribution of the Tristichaceae and Podostemaceae. These families afford an excellent test case for the question of age or youth, for owing to their peculiar morphology one can say with reasonable approach to certainty which are the older forms. He would be a bold man who would say that such forms as Lawia in the one family, or Castelnavia in the other, with their violently dorsiventral structure, shown in the lichen-like vegetative 
body and the extraordinarily modified flowers, were older than such forms as Tristicha or Podostemon, which are almost radially symmetrical, and come near to the ordinary type of submerged water plant. Yet the latter are widespread and almost universal, covering the whole range of distribution of the families, while the violently dorsiventral forms are all endemic to comparatively small areas, Lawia, for example, occurring from Ceylon to Bombay, Castelnavia in the Araguaya and one other river in Brazil. It is impossible to talk of local adaptation in these plants, as I have elsewhere pointed out (18); there is nothing to be adapted to. The non-dorsiventral forms are just as common as the dorsiventral, whether in slowly or in swiftly moving water. This family is perhaps the most promising in all the flowering plants in which to study evolution or anything connected therewith; the moment that I saw them growing in the river at Peradeniya, I realized that there was an unrivalled group for the study of Adaptation, in which at that time I was a whole-hearted believer.

\section{Mutation.}

Later, Mr. Ridley objects to the mutation theory, and quotes against it numerous examples which show that he confuses mutations with varieties, and with the direct effect of changed conditions, and that he does not clearly distinguish between infinitesimal variations and large changes. He says that 'an organism ... produces ... varieties, which if more suitable to the surrounding conditions than the parent form are selected...' Does an infinitesimal variation at once produce a variety?

Mr. Ridley does not seem to be quite sure whether he will have Natural Selection with infinitesimal variations or with large changes; he evidently has an uneasy feeling that if he adopt the latter he rules Natural Selection out of court $(10,11)$, for if it cannot act upon a small beginning, nor determine that a large variation in one direction shall be followed by another in the same direction, it cannot be the determining factor in the production of the finished article, nor can it be its explanation.

So long as we keep to infinitesimal variations, in the literal sense in which they were understood until the coming of the mutation theory, it is quite simple to evolve anything, provided (I) that the variations are fully hereditary without regression, which we now know them not to be, (2) that they are differentiating, and not simply linear, (3) that the necessary variations appear, and (4) that Natural Selection can act-that their appearance gives sufficient advantage to the plant to ensure their survival in at least a majority of cases. But, if we once adopt large changes, the whole case is altered. We know no reason why a large change in one direction should be followed by further large changes in the same direction. There is nothing for it but to admit that the whole of a specific or perhaps even generic change may appear, but Natural Selection has nothing to do with its 
appearance; it simply kills out any that are really disadvantageous; and that, it now appears clearly from my work on age and area, it does in the very early stages, when a species is represented by a few individuals only.

The supporters of Natural Selection do not clearly distinguish between post hoc and propter hoc. Does Mr. Ridley imagine that the spines on one of the Metroxylons (p. 562) began by infinitesimal variation ? If so, did the infinitesimal spines make any difference to the survival of the species? Had the pigs more delicate mouths in those days? Or were there any pigs? But if they did not begin in this way, where did Natural Selection come in? The spines are suddenly produced, and being uninjurious, are not weeded out by Natural Selection, but Natural Selection did not produce them, and cannot be their explanation. The other species, with no spines, survives also.

Does Mr. Ridley suggest that the Vitex on p. 564, which on being moved to Singapore proved to be $V$. trifolia, was a distinct species? Did it refuse to cross with $V$. trifolia?

For many years I have kept a note-book in which I have noted down, under the various letters of the alphabet, various questions which may be proposed to the supporter of Natural Selection, and will quote, for Mr. Ridley to answer if he can, a few of those under A :

How did the following commence, and what advantage was gained by the rudimentary beginning, sufficient to ensure the completion of the organ in question?

Phyllodes in Acacia?

Sensitive leaves in Aldrovanda?

Bulbils in many species of Asplenium?

Thorny roots in Acanthorhiza?

Simple, lobed, and compound leaves in different Acers?

Dehiscent berries in Akebia?

Reversed leaves in Alstroemeria?

The formation of adventitious embryos?

Hooked bracts in Arctium?

Cauliflory in some Artocarpus?

Scaly pappus in Achyrachaena?

Anisophylly in many plants?

Sympodia in Ancistrocladus?

Pollinia in Asclepiadaceae?

If these, or most of them, arose, as one must believe, directly at one operation, where does Natural Selection come in as formative or explanatory? As they are not harmful mutations it allows them to survive, but that is the end of its activities, so far as we can see. Natural Selection cannot be regarded as the formative agent for differences in individual species, as has been done 
in the past; its operations are much more of a destructive nature than of a constructive, and are shown especially in the killing out of individual mutations.

With regard to the Castelnavias which I mention in one of my papers (6, p. I5), Mr. Ridley appears to think that what he terms study in the field rather than the library will some day show differences in the conditions of life sufficient to account for the evolution under Natural Selection of seven different species in successive cataracts in the same river. In the case of the Podostemaceae of India and Ceylon my studies in the field and laboratory $(15,16)$ together amounted to an average of five hours a day for six years, or an average of 500 hours (four months) for each species. To how many of the species he quotes has Mr. Ridley given that amount of time? Since I902 I have never ceased to observe these plants, and in Brazil I gave considerable time to their study. During the first period I was an enthusiastic supporter of Natural Selection; but the more I studied them the more I became convinced that they lived under identical conditions, and that Natural Selection had nothing to do with their evolution. In this paper I give a very good crucial case drawn from these families. If the Castelnavias are to be evolved by Natural Selection in response to local differences in conditions, then evolution must be very exact to the most minute differences, ${ }^{1}$ and how can one have species that range even over a square mile of varied surface? They live on the same rock substratum in a short stretch of the Araguaya river, and have no external competition whatever, and no differences of conditions can be found between any two except in the imagination - a faculty which was somewhat pushed to excess in the studies of Adaptation which were so largely carried on until the last few years of last century.

Mr. Ridley states that it is only Natural Selection that can answer questions, but, as I have already pointed out, it does so, like the hypothesis of Special Creation which preceded it, by invoking incomprehensibility. Mr. Ridley himself gives a good illustration of this on p. 573, where he states: 'The obvious reason why wide range ... involves greater commonness is that for some reason the plant has advantages which enable it to spread....' He avoids replying to the second half of my question, by the way. I said that the reply of the Natural Selectionists to the inquiry Why are Ceylon-Indian species commoner than endemics? was that it is because they have a wider range. When asked why the 'wides' have a range in Ceylon that is yet larger than that of the Ceylon-Indians, they can only answer that it is because their range abroad is also larger.

The reply of the Natural Selectionist is always, stripped of its verbiage, ' for some reason this is so - the reply of the Special Creationist. On

${ }^{1}$ Such, for instance, as the different angle of sunshine at one cataract and the next, or the difference in mean temperature between them. 
p. I 5 of my Ceylon paper (6) are examples of questions of the kind to which the reply is always such, and Mr. Ridley judiciously avoids these. I do not pretend, and have nowhere pretended, that any modern hypothesis gives a proper explanation of adaptation, which at the moment is perhaps the greatest difficulty of all; but there is no doubt that Natural Selection does not do it satisfactorily. The how and the why of evolution have yet to be worked out, and that work may be prevented from losing itself in one or two blind alleys, at any rate, by the light thrown on geographical distribution by the present and other researches.

The bulk of Mr. Ridley's attack on mutation may be answered by referring him to the published work of de Vries, which one cannot but infer from his paper that he has not read with great care. Throughout his paper he gives instances of large changes as infinitesimal variations, and then proceeds to kill the case in the summary by saying that the mutation theory is not in accordance with the facts.

He quotes the literature of the fertilization of flowers as a case proving that specific differences are useful. I myself was one of the very last botanists to work seriously at floral mechanisms, good-naturedly chaffed by my friends for adhering to a theory (Natural Selection and detailed Adaptation) which was steadily going the way of all flesh. Having been brought up in the strictest Darwinian school, I devoted five years to this subject and to other 'adaptations'. For this I am now most grateful, for it has shown me the Natural Selection position thoroughly from the inside. But as a result I can only say that it is very rarely indeed that a specific character can be shown to have any importance in this connexion. The plant can sometimes make use of a specific character when there, but it did not acquire that character because of its usefulness.

I have now dealt with the chief points of Mr. Ridley's attack, and may go on to point out that he has made no attempt to parry my own, other than by bringing up exceptions, which have no bearing on figures of large numbers of plants, such as I was dealing with. The attack being upon my Ceylon work, I have confined my answer to that, though New Zealand would have supplied a much better one. He makes no effort to explain why the figures are graduated in opposite directions for endemics and wides; why the Ceylon-Indian species are intermediate in rarity; why the various species show a chain-mail pattern of distribution (6, maps on p. I2); why the endemics are 'dying out' in a mechanical way, one family or genus like another, whether they have or have not allied wides beside them; why every family and larger genus (especially in New Zealand) shows the same general plan of distribution; why the area in which occur the maximum number of wides coincides with that in which occur the maximum of endemics; and so on. Nor does he attempt to meet my arithmetical argument against 
Natural Selection (6, pp. 6-16), which may be exactly repeated with illustrations drawn from the flora of New Zealand, where the Ceylon estimates are replaced by actual measurements. If these questions cannot be parried, the case for Natural Selection is a very forlorn hope.

A very valuable result of Mr. Ridley's paper is the stress which it lays upon the various causes which may modify the action of my age and area law. Some of these causes probably come into action in almost every single case of any one individual species, though upon large numbers, and in the long run, they cancel out. All might have been covered had I added to my tentative statement of the law the phrase 'so long as conditions remain constant', or words to that effect. We may enumerate some of these factors here, but the list will no doubt be largely added to. The law itself, however, in my opinion, will stand as valid, when it is applied, like Mendel's, only to groups of forms.

Chance (the operation of causes as yet not understood);

Action of man in opening up a country, cutting of forest, exploring, making fires, \&c., \&c. ;

Interposition of barriers, such as mountains, broad rivers, deserts, arms of the sea, sudden changes of climate from one district to the next, and the like ;

Geological changes, especially if involving change of climate;

Serious changes of climate ;

Natural selection;

Local adaptation (a species may have a peculiarity which is useful in one country and valueless in another);

Dying out of occasional old species ;

Arrival of a species at its climatic limit;

Density of vegetation upon the ground at the time of arrival of a species;

Presence or absence of mountain chains in the land over which the species has to travel in arriving;

Relative width of the union between the country of departure and that of arrival (the wider it is the more rapid may be the spread of the species in the new country),

and so on. There are numerous factors which may exert a disturbing influence, but that no more affects the validity of my law than does the resistance of the air, which prevents a thing from falling in exact accordance with the law of gravity, affect the validity of that law. I am far from denying that in individual cases plants may be relic endemics, or may have had their area of distribution greatly extended by the action of Natural Selection, or in other ways altered ; but in large numbers and the long run such things do not show in my figures, which indicate that the overwhelming factor in distribution is simply age. 


\section{SUMMARY.}

The paper is chiefly a reply to the criticisms of my Ceylon work by $\mathrm{Mr}$. H. N. Ridley in the October Annals, but contains a few new facts also. Mr. Ridley's criticisms are in reality answered in advance by my work on New Zealand.

It is shown that the Ceylon results cannot be accidental nor determined solely by the numbers of specimens in the herbarium, and that the figures are far too numerous to be disturbed by bringing up exceptions, as Mr. Ridley does.

Man's action, changes of climate, and similar disturbing factors, were not sufficiently emphasized in my Ceylon paper, but have since been dealt with.

Evidence is then given to show that the endemic species are on the whole the youngest, not the oldest, in a country. There may be relics also, but they are not numerous enough to show in the figures. This is supported by two crucial cases: one showing that the wides of New Zealand take no notice of Cook's Strait in their distribution, while the endemics do; the other based on the local distribution of the highly modified Tristichaceae and Podostemaceae and the cosmopolitan distribution of the little modified forms.

Mr. Ridley's objections to the mutation theory are then considered, and it is shown that the supporters of Natural Selection do not clearly distinguish between post hoc and propter hoc. Natural Selection cannot explain the origin of the peculiarities which distinguish plants, but can only preserve or destroy them when once formed. The reply of the Natural Selectionist to queries invokes incomprehensibility, as did formerly that of the Special Creationist.

Finally a list is given of factors which may modify the action of my law of age and area.

\section{LITERATURE QUOTED.}

1. Ridley, H. N. : Endemism and the Mutation Theory. Ann. Bot., vol. xxx, I916, p. 55 I.

2.

3. Thwaites, G. H. K. : Enumeratio Plantarum Zeylaniae. London, I864.

4. Trimen, H.: Flora of Ceylon. London, I893-1900.

5. Willis, J. C. : The Endemic Flora of Ceylon. Phil. Trans., B, vol. ccvi, I9I 5, p. $30 \%$.

6. - The Evolution of Species in Ceylon, with reference to the Dying Out of Species. Ann. Bot., vol. xxx, I9I6, p. I.

7. - The Distribution of Species in New Zealand. Ann. Bot., vol. xxx, I9I6, p. 437 . 
8. Willis, J. C. : Catalogue of Ceylon Plants. London, I9I I.

9. vol. iii, I906, p. 27 I.

10. : Some Evidence against ... Natural Selection. Ann. R. B. Gardens, Perad., vol. iv, I907, p. I.

11. : Further Evidence ... Ann. R. B. Gardens, Perad, vol. iv, 1907, p. I7.

12. : The Floras of Hill-tops in Ceylon. Ann. R. B. Gardens, Perad., vol. iv, I908, p. I3I.

13. : Geographical Distribution of the Dilleniaceae ... Ann. R. B. Gardens, Perad., vol. iv, 1908, p. 69.

14. — Flora of Naminakuli-kanda. Ann. R. B. Gardens, Perad., vol. v, I9I I, p. 2 I 7.

15. : Revision of the Podostemaceae of India and Ceylon. Ann. R. B. Gardens, Perad., vol. i, I902, p. I8I.

16. : Studies in the Morphology and Ecology of the Podostemaceae of Ceylon and India. Ann. R. B. Gardens, Perad., vol. i, I902, p. 267.

17. $:$ The Origin of the Tristichaceae and Podostemaceae. Ann. Bot., vol. xxix, 1915 , p. 299.

18. Soc., B, vol. lxxxvii, I9I4, p. 532 .

19. $\quad$ and Smith, A. M.: Additions and Corrections to the Ceylon Flora. Ann. R. B. Gardens, Perad., vol. v, igi I, p. I75. 


\section{$2 \mathrm{BHL}$ Biodiversity Heritage Library}

Willis, J. C. 1917. "The relative age of endemic species and other controversial points." Annals of botany 31, 189-208.

https://doi.org/10.1093/oxfordjournals.aob.a089639.

View This Item Online: https://www.biodiversitylibrary.org/item/232813

DOI: https://doi.org/10.1093/oxfordjournals.aob.a089639

Permalink: https://www.biodiversitylibrary.org/partpdf/320182

\section{Holding Institution}

Smithsonian Libraries

\section{Sponsored by}

Biodiversity Heritage Library

\section{Copyright \& Reuse}

Copyright Status: Not in copyright. The BHL knows of no copyright restrictions on this item.

This document was created from content at the Biodiversity Heritage Library, the world's largest open access digital library for biodiversity literature and archives. Visit BHL at https://www.biodiversitylibrary.org. 